\title{
Current Management of Locally Advanced Junction Esophagogastric Adenocarcinoma
}

\author{
Rodica Birla, Petre Hoara, Andrei Caragui, Marica Cristian, Silviu Constantinoiu
}

Carol Davila University of Medicine and Pharmacy, Bucharest, Romania

General and Esophageal Surgery Department, Center of Excellence in Esophageal Surgery, Sf. Maria Clinical Hospital, Bucharest

Corresponding author:

Rodica Birla,MD

General and Esophageal Surgery Department, Center of Excellence in Esophageal Surgery, Sf. Maria Clinical Hospital, Bucharest Bucharest, Romania

E-mail: birlarodica@yahoo.com

\section{Rezumat}

Managementul actual în adenocarcinomul de joncțiune esogastrică avansat local

Adenocarcinomul de joncțiune gastroesofagianã (GEJ) este mai frecvent în țãrile vestice. Chimioterapia preoperatorie sau chimioradioterapia este indicatã la pacienții cu boala avansată local. Studii actuale sugerează rate mai mari de rezecție cu intentie curativă şi rate reduse de recurență locală la pacienții cu terapie neoadjuvantă: chimioterapie asociata sau nu cu radioterapie. Rolul terapiei țintite în cadrul terapiei neoadjuvante este în curs de investigare.

Cuvinte cheie: adenocarcinomul de joncțiune esogastrică, radiochimioterapie, chimioterapie, chirurgie

\section{Abstract}

Adenocarcinoma of the gastroesophageal junction is more common in the West. Preoperative chemotherapy or chemoradiotherapy is performed for locally advanced disease. Recent studies are suggesting higher rates of curative resection and reduced rates of local recurrence in patients with neoadjuvant combination of chemotherapy and radiation therapy. The role of targeted agents in neoadjuvant therapy is under investigation.

Key words: junction esophagogastric adenocarcinoma, chemoradiotherapy, chemotherapy, surgery 


\section{Introduction}

An ongoing increase in adenocarcinoma of the gastroesophageal junction has occurred over the last decades (1). Surgical treatment is the main therapeutic option. In these patients the risk of incomplete surgical resection and local tumor recurrence is significant because of the anatomy of the mediastinum and GEJ. Neoadjuvant therapy is now routinely included given the poor outcomes with surgical management alone.

Beside the TNM classification, it was agreed that adenocarcinoma of the gastroesophageal junction is classified best according to Siewert. Preoperative radiochemotherapy (RCT) is the preferred treatment for Siewert type I and II tumors. For locally advanced adenocarcinoma $(\geq \mathrm{T} 3 \mathrm{~N}+)$, the preferred treatment modality was pre- and postoperative chemotherapy (CT). For type III tumors which may be considered as gastric cancer, perioperative chemotherapy is the majority approach (2). Some authors consider for clinical T2N0 adenocarcinoma, surgery alone as a standard treatment approach without neoadjuvant therapy (3). But recent studies show that current preoperative staging of patients with T2N0 adenocarcinoma may lead to clinical understaging in a substantial proportion of patients (4). Because of pretherapeutic staging was considered highly unreliable the approach of $\mathrm{T} 2 \mathrm{~N}+$ or even T2N0 tumors have to done similar with $\mathrm{T} 3 \mathrm{~N}+(2)$. However some trials have not confirmed a clear survival benefit of a preoperative therapy compared to a surgery alone for T2N0 tumors (5). There is on-going controversy about treating these patients with preoperative therapy.

\section{Chemotherapy and Chemoradiotherapy}

The role of multidisciplinary approach for GEJ cancer is still a matter of debate. Neoadjuvant or preoperative therapy has been evaluated largely in clinical T3 or node positive disease. Avantages of neoadjuvant therapy are: affords the possibility of downsizing tumors and improving rates of $\mathrm{R} 0$ resection, a significant number of patients are unable to receive post- operative treatment because of poor tolerance or postsurgical complications, may allow modification of treatment based upon response (PET). The MAGIC trial of perioperative chemotherapy in gastroesophageal cancer in the UK reported a survival benefit for perioperative chemotherapy. Patients with clinical stage II or higher adenocarcinomas of the GEJ or stomach were treated, but the majority of the 503 patients treated (74\%) had gastric primaries. Surgery alone was compared to 3 cycles of epirubicin, $\mathrm{CF}$, and infusional 5-FU (ECF) pre- and 3 cycles postsurgery. Tumor down staging was modest with chemotherapy, with more T1-2 tumors in the chemotherapy group compared to surgery alone (52\% vs. $37 \%$ ) and more $\mathrm{N} 0-1$ tumors $(84 \%$ vs. $72 \%)$. Similar numbers of patients had N0 disease with or without chemotherapy (31-27\%). Progression free and overall survival were superior for the chemotherapy arm, with a 5-year overall survival increased from $23 \%$ to $36 \%$. Based on this trial, perioperative ECF became a new care standard in Western Europe and the US in esophagogastric cancer (6).

Concern about the adequacy of preoperative chemotherapy alone in esophageal and GEJ cancer patients continues given persistently lower rates of $\mathrm{R} 0$ resection for GEJ cancers reported in contemporary trials. Two recent trials from the UK treated 1,900 patients with either preoperative CF or ECF, including 1,600 patients with esophageal and GEJ adenocarcinoma $(7,8)$.

Relatively low rates of $\mathrm{R} 0$ resection of 57$67 \%$ were reported for Siewert I GEJ cancers, compared to $87 \%$ for more distal gastric cancers, on these studies using preoperative chemotherapy. These results have continued the debate about the potential need to include preoperative radiation therapy to ensure $\mathrm{R} 0$ resection for patients with tumors involving the esophagus and GEJ.

Although the impact of chemotherapy on pre- and perioperative treatment of esophageal and gastric cancer has been extensively studied two randomized trials have changed the practice in the US and Western Europe $(9,10)$. 
Furthermore, a metanalysis with 2422 patients evaluated surgery vs preoperative CT or chemoradiotherapy. It showed a significant survival benefit for preoperative treatment over surgery alone with an hazard ratio of 0.82 and a 5-year absolute overall survival gain of $9 \%(23 \%$ vs $32 \%)(11)$.

In the FNCLCC and FFCD trial, 224 resectable esophageal, GEJ and gastric cancer patients (more than $60 \%$ of patients were GEJ) were randomized to either upfront surgery or perioperative CT (two or three cycles of cisplatin and 5-fluorouracil) and surgery to assess the benefits in terms of OS and disease-free survival (DFS) yielded by CT. Unfortunately, the study was closed earlier due to difficulties in patient enrollment, although it clearly demonstrated a better 5-year OS and DFS in the CT-treated arm (38\% vs $24 \%$, and $34 \%$ vs $19 \%$, respectively) (12).

A large clinical trial carried out in the United Kingdom have been made in four hundred consecutive patients (approximately $70 \%$ were GEJ type I or II) were treated with preoperative CT (cisplatin and 5-fluorouracil, or ECF, or ECX). OS was shown to be significantly prolonged in patients with downstaged tumors (13).

The potential advantage deriving from preoperative CRT is suggested by several phase II studies and by subgroup analysis of four randomized trials, in which patients with all types of esophageal cancer received CRT followed by surgery or surgery alone. However, the statistical power of these trials was weak because of the low numbers of true GEJ cancers (14).

A trial attempting to compare pre-operative chemoradiation to pre-operative chemotherapy was reported by the German POET trial (PreOperative Chemotherapy or Radiochemotherapy in Esophagogastric Adenocarcinoma Trial). In the German study, 119 patients with GEJ cancer (uT3-T4 NxM0) were randomly assigned to receive either CRT (cisplatin, 5-fluorouracil, and leucovorin - PFL - followed by cisplatin and etoposide, plus a total dose of 30 Gy of radiation) and surgery or CT plus surgery. Although the study was closed earlier than planned without reaching a statistically significant survival benefit, outcomes were better in the CRT and surgery arm in terms of 3 -year survival $(47.4 \%$ vs $27.7 \%)$ and rates of pathologic complete response (pCR: $15.6 \%$ vs $2 \%)$ and tumor-free lymph nodes (64\% vs $37.7 \%)(15)$.

Another milestone phase III study was the CROSS trial, in which 366 esophageal or GEJ cancer patients received CRT (weekly carboplatin and paclitaxel, plus 41.4 Gy of radiation) followed by surgery or surgery alone. Median OS was significantly longer in the CRT and surgery arm than in the surgery alone group (49.4 mo vs 24.0 mo, respectively); in addition, the rate of $\mathrm{pCR}$ was $29 \%$ following multimodal therapy. Node-positive disease remained in $31 \%$ after chemoradiation but in $75 \%$ with surgery alone. Disease was T2 or greater in 51 vs $92 \%$. Gross total resection with negative margins was achieved for 92 vs $69 \%$. Of note, only $20 \%$ of the patients had a true GEJ cancer (16).

In other study, preoperative CRT (with FOLFOX regimen and 45 Gy of radiation) was shown to be safe in 41 GEJ patients, albeit efficacy was mild (17).

A metanalysis shows that in patients with adenocarcinoma of the esophagus and GEJ, preoperative CT improves OS when compared to surgery alone. The greater effectiveness of the treatment was, however, observed with CRT (18).

In the US, one additional alternative is post-operative chemoradiation for GEJ and gastric cancers undergoing up front resection, based on the results of the Intergroup 116 trial. This trial randomized 556 patients $(20 \%$ of whom had tumors that involved the GEJ) to adjuvant chemotherapy and chemoradiation with bolus 5-FU/leucovorin to observation alone following surgery. Overall survival was improved by $10 \%$ favoring postoperative therapy. This trial had relatively poor surgical quality, with $54 \%$ of patients having less than a D1 or D2 resection. Because many patients after esophagogastrectomy fail to recover to the point of tolerating post-operative therapy, and given the potential downstaging achieved by preoperative therapy, postoperative chemo- 
radiotherapy for esophageal or GEJ cancers is rarely applied $(19,20)$.

For patients with a poor performance status or with advanced age and medical comorbidities, given a potentially high risk for either mortality or severe complications from esophagectomy, definitive chemoradiotherapy without surgical resection is considered. Patients with local regional recurrence after definitive chemoradiotherapy may be considered for salvage surgery. After salvage surgery, a higher mortality rate is reported as well as increased rates of anastomotic leak and pulmonary complications $(21,22)$.

\section{Targeted Therapy}

Genomic analyses of gastroesophageal cancers using broad genomic screening for gene mutation, amplification, and deletions have recently been reported. Remarkably similar genomic profiles have emerged from genomic studies evaluating Western and Asian patients with gastric cancer $(23,24)$.

Molecular subgroups identified in US studies under The Cancer Genome Atlas (TCGA) project, includ:

I. genomically unstable tumors with higher rates of receptor associated tyrosine kinase pathway gene amplification (HER2, EGFR, MET, FGFR), high rates of p53 mutation, and amplification of VEGFA and cell cycle pathways;

II. genomically stable tumors with relatively few mutations and presence of $\mathrm{CDH}^{-1}$ and RHO-A mutation;

III. tumors with higher rates of gene hypermethylation leading to a higher mutation burden with high rates of microsatellite instability (MSI);

IV. tumors associated with EBV infection and amplification of potential immune related pathways including over expression of PDL-1 and PDL-2 ligands.

Correlating anatomic location and conventional histology, the vast majority of esophageal and GEJ adenocarcinomas fall under the genomically unstable category and $50 \%$ of distal gastric cancers fall into this category (25).

Therapeutic implications of these subgroups include studying receptor associated kinase agents in genomically unstable tumors, and immune checkpoint inhibitors in MSI or EBV associated tumors given the higher mutational burden and higher expression of PDL-1 and PDL-2 ligands in these subgroups. A recent genomic analysis of 129 esophageal and GEJ adenocarcinomas identified three targetable subgroups, including enrichment for a BRCA like signature, tumors with a higher potential mutational burden, and tumors with a mutational pattern consistent with an aging imprint, with potential therapeutic implications including use of DNA damaging agents and immune checkpoint inhibitors (26).

Stratification of patients on the basis of molecular profile will be obligatory in future trials because of the potential for intrinsic biologic differences in these subsets.

Targeted therapy trials have largely focused on the VEGF pathway, and receptor associated tyrosine kinase pathways such as EGFR, HER2, and MET. In metastatic disease, response and survival benefits have been observed in phase III trials of the agent ramucirumab targeting the VEGFR2 receptor, and trastuzumab targeting the HER2 receptor $(27,28,29)$.

The addition of targeted agents to chemoradiotherapy, including two trials adding the EGFR-targeted agent cetuximab to chemoradiotherapy failed to improve any outcome (30,31).

A pilot trial combining the vascular endothelial growth factor (VEGF) targeted agent bevacizumab with chemoradiotherapy (32), and a randomized trial adding bevacizumab to preoperative chemotherapy (33) also failed to improve outcome.

Trials combining the EGFR inhibitors cetuximab or the VEGF inhibitor Bevacizumab have failed to improved outcome when added to either chemoradiotherapy or preoperative chemotherapy $(30,31,33)$. RTOG trial 1010 (NCT01196390) evaluated the addition of trastuzumab to preoperative carboplatin, paclitaxel, and radiation therapy in HER2 positive esophageal and GEJ cancers. Results from a trial combining trastuzumab with pre- 
operative chemoradiotherapy in HER2 positive esophageal and GEJ cancer are pending. 20\% of GEJ adenocarcinoma have overexpressed HER 2 (Fig. 1).

Results from a trial combining trastuzumab with preoperative chemoradiotherapy in HER2 positive esophageal and GEJ cancer are pending.

Agents targeting immune checkpoint pathways mediated by the CTLA- 4 and PD- 1 pathways have also undergone recent extensive evaluation. Recent phase II and phase III trials indicate a small but consistent signal of activity for anti PD-1 or PDL-1 agents in esophageal and GEJ cancers, with response rates ranging from $10-20 \%$ with a suggestion of higher response rates in patients with overexpression of PDL-1 (34).

A recent phase III trial in gastric and GEJ cancer patients refractory to chemotherapy compared supportive care to treatment with the anti PD-1 agent nivolumab (35). Overall survival as well as response rate and progression free survival were improved for patients treated with nivolumab compared to placebo. These agents will likely be incorporated into clinical trials of neoadjuvant or adjuvant chemotherapy and radiation therapy.

Stratification of patients on the basis of molecular profile will be obligatory in future trials because of the potential for intrinsic biologic differences in these subsets.

\section{Surgical Treatment}

Resection of the esophagus with en bloc lymphadenectomy is the cornerstone of curative treatment for patients with locally advanced junction adenocarcinoma (36).

In the last decade in the General and Esophageal Surgery Clinic of Saint Mary Hospital Bucharest, more than 400 patients with GEJ adenocarcinoma have been treated, almost $40 \%$ have experienced locally advanced tumors with a $52 \%$ resectability rate and starting in 2014 we introduced neoadjuvant treatment in these patients.

Standard open approaches have included a thoracotomy for excellent thoracic exposure

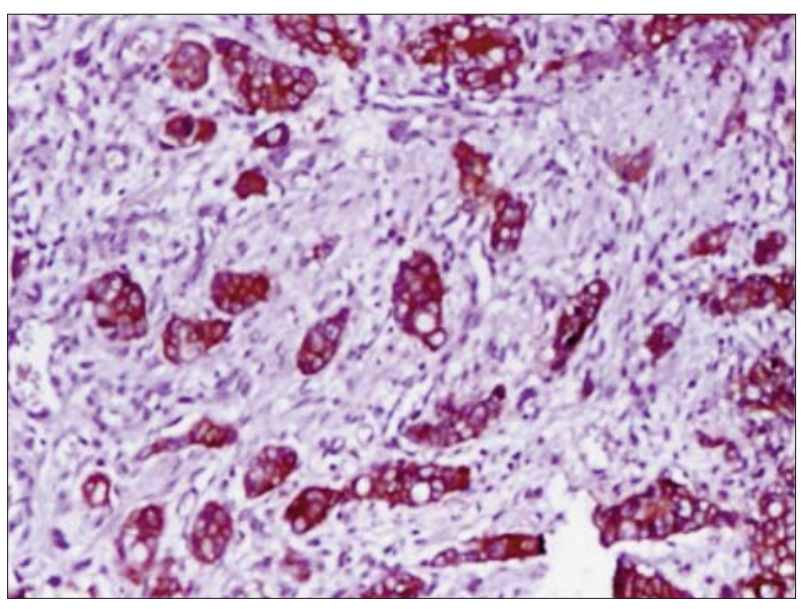

Figure 1. Immunohistochemistry HER2 overexpressed (3+) in GEJ adenocarcinoma

(St Mary Hospital Surgery Clinic Collection)

allowing extended mediastinal and wide circumferential dissections. The Ivor-Lewis approach achieves access with a right posteriolateral thoracotomy and midline laporotomy, with reconstruction after resection using an intrathoracic anastomosis. The McKeown approach adds a cervical incision allowing a cervical anastomosis and may be associated with reduced serious complications from anastomotic leaks that may be easier to treat in the neck (Fig. 2).

Transhiatal resection is validated and suitable for Siewert I/II adenocarcinoma. A transhiatal resection achieves access by laparotomy

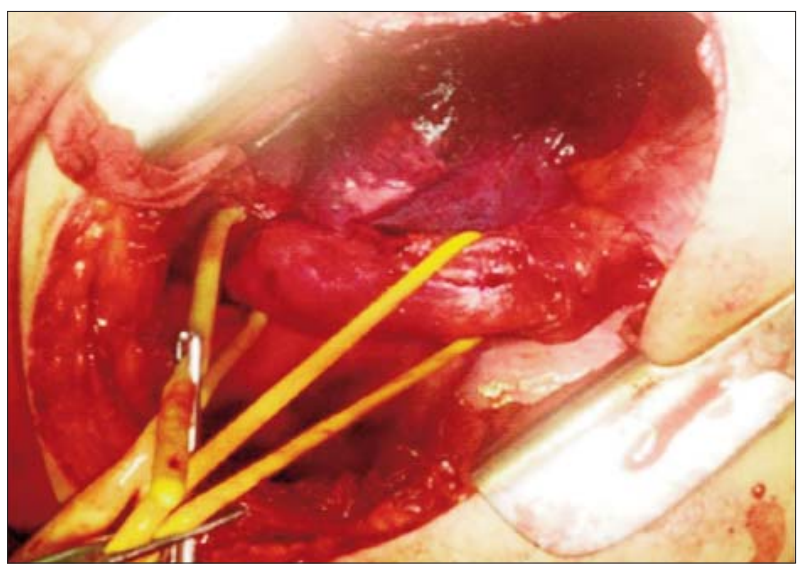

Figure 2. Triple approch - thoracic stage - esophageal dissection (St Mary Hospital - Surgery Clinic Collection) 


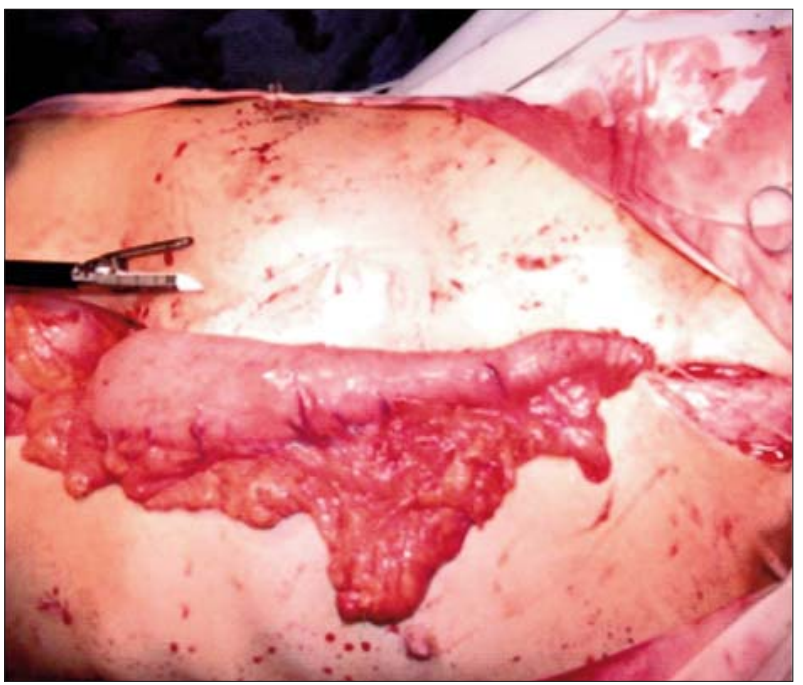

Figure 3. Transhiatal resection and gastric tube (St Mary Hospital - Surgery Clinic Collection)

and cervical incision followed by gastric pull-up and cervical anastomosis (Fig. 3).

Lymphadenectomy is performed to intraabdominal nodal groups and parahiatal and proximal lesser curvature and also paraesophageal nodes up to the level of the inferior pulmonary vein.

Transthoracic and transhiatal approaches are the two major surgical approaches used worldwide. However, considerable debate exists on the superior benefits of the two approaches regarding their efficacy and safety.

A transthoracic esophagectomy with twofield lymph node dissection and gastric conduit reconstruction is the preferred procedure for resection of Siewert I adenocarcinoma. Transhiatal esophagectomy, without thoracotomy was designed to reduce postoperative morbidity and mortality by avoiding thoracotomy (37).

Another study indicated a shorter hospital stay, lower 30-days hospital mortality and decreased pulmonary complications with the transhiatal approach compared with the transthoracic approach. Moreover, a potential survival benefit was achieved for type III tumors using the transhiatal approach (38).

A randomized clinical trial, comparing an extended transthoracic resection with a transhiatal approach showed that transhiatal esophagectomy was associated with lower morbidity and shorter intensive care unit and hospital stay compared to transthoracic esophagectomy (39).

Treatment in high-volume centers with experienced surgeons and the availability of critical-care support are associated with improved outcomes and lower morbidity and mortality $(40,41)$.

Compared with transhiatal resection, transthoracic esophagectomy for esophageal adenocarcinoma indicated a trend towards better 5-year survival (38).

The left thoracic approach (Adam and Phemister, 1938; Churchill and Sweet, 1942) was the first standard approach for the GEJ tumors. In the GEJ tumors, upper polar gastrectomy with intrathoracic Sweet-type gastric anastomosis can be practiced on the left transthoracic approach with frenotomy. It is conditioned by gastric resection at least $5 \mathrm{~cm}$ distal to the tumor to obtain R0. It is indicated in elderly or elderly patients with contraindications for wider interventions. The disadvantages of this technique are: the high incidence of gastroesophageal reflux and the lack of oncological radicality in terms of lymphodisection.

Toraco-freno-laparotomy, although widely used in the past for the GEJ tumor due to good exposure to the GEJ, but creates an instability of the thorax and the phrenotomy adds significant damage to the respiratory mechanics. It was considered an exceptional approach (42). In Siewert II/III tumors, total gastrectomy with Y anastomosis through abdominal approach can be practiced when thoracotomy is contraindicated. (Hill method) (43).

Some authors use transhiatal esophagectomy in the block with total gastrectomy and abdominal lymphadenectomy with restoration of digestive continuity by colon interposition (the MorenoGonzales procedure), which is exceptional recommended due to the high surgical risk.

Minimally invasive esophagectomy, and more recently robotically assisted esophagectomy, are emerging as surgical alternatives to open esophagectomy (44).

For junction adenocarcinoma there are no clear oncologic benefit of either esophagectomy or gastrectomy. However, gastrectomy seems to 
be accompanied with better quality of life (45).

Lymph node clearance is regarded as a predominant prognostic factor for cancer of the esophagogastric junction. The removal of lymph nodes in the mediastinum is the primary goal of surgery. However, the optimum extent of lymph node resection is still controversial (46).

Transthoracic and transhiatal approaches led to a similar rate of lymphadenectomies in the abdominal cavity. However, transthoracic resections require a thorough mediastinal nodal dissection with an esophagectomy of sufficient length; therefore, transhiatal esophagogastrostomy is performed in the neck without cervical lymphadenectomy, leading to insufficient lymphadenectomy in the thoracic cavity.

In a study, was reported no significant difference between the groups - transthoracic vs transhiatal -with regard to lymph node resections (38).

Although other studies reported less lymph node dissection in the transhiatal procedure than in the transthoracic procedure. This result may have been caused by surgeons's indirect vision in the operation (47).

\section{Conclusions}

Preoperative Siewert type establishing is necessary to select the management in locally advanced esogastric junction adenocarcinoma. Multiple characteristics - tumors, disease- and patient-specific, must be considered in selecting the optimal treatment for these patients. In current practise, the most important is the TNM stage of the tumor at the time of diagnosis. For patients with locally advanced disease without distant metastases, the most common treatment is neoadjuvant CRT, followed by resection and lymphadenectomy. Stratification of patients on the basis of molecular profile will allow to choose target therapy.

\section{References}

1. Crew KD, Neugut Al. Epidemiology of upper gastrointestinal malignancies. Semin Oncol. 2004;31(4):450-64.

2. Lutz MP, Zalcberg JR, Ducreux M, Ajani JA, Allum W, Aust D,et al First St Gallen EORTC Gastrointestinal Cancer Conference 2012 Expert Panel. Highlights of the EORTC St. Gallen International Expert Consensus on the primary therapy of gastric, gastro- esophageal and oesophageal cancer - differential treatment strategies for subtypes of early gastroesophageal cancer. Eur $\mathrm{J}$ Cancer. 2012;48(16):2941-53.

3. Markar SR, Gronnier C, Pasquer A, Duhamel A, Beal H, Théreaux J, et al. Role of neoadjuvant treatment in clinical T2NOMO oesophageal cancer: results from a retrospective multi-center European study. Eur J Cancer. 2016;56:59-68. doi: 10.1016/j.ejca.2015.11.024.

4. Dolan JP, Kaur T, Diggs BS, Luna RA, Sheppard BC, Schipper PH, et al. Significant understaging is seen in clinically staged T2NO esophageal cancer patients undergoing esophagectomy. Dis Esophagus. 2016;29(4):320-5. doi: 10.1111/dote.12334.

5. Mariette C, Dahan L, Mornex F, Maillard E, Thomas PA, Meunier B, et al. Surgery Alone Versus Chemoradiotherapy Followed by Surgery for Stage I and II Esophageal Cancer: Final Analysis of Randomized Controlled Phase III Trial FFCD 9901. J Clin Oncol. 2014;32(23):2416-22. doi: 10.1200/JC0.2013.53.6532. Epub 2014 Jun 30 .

6. Cunningham D, Allum WH, Stenning SP, Thompson JN, Van de Velde CJ, Nicolson M, et al. Perioperative chemotherapy versus surgery alone for resectable gastroesophageal cancer. N Engl J Med. 2006;355(1):11-20.

7. Alderson D, Langley RE, Nankivell MG, et al. Neoadjuvant chemotherapy for resectable oesophageal and junctional adenocarcinoma: Results from the UK Medical Research Council randomised OEO5 trial (ISRCTN 01852072). J Clin Oncol 2015;33 suppl:abstr 4002.

8. Cunningham D, Stenning SP, Smyth EC, Okines AF, Allum WH, Rowley $S$, et al. Perioperative chemotherapy with or without bevacizumab in operable oesophagogastric adenocarcinoma (UK Medical Research Council ST03): primary analysis results of a multicentre, open-label, randomised phase 2-3 trial. Lancet Oncol. 2017;18(3):357-370. doi: 10.1016/S1470-2045(17)30043-8. Epub 2017 Feb 3.

9. Orditura M, Galizia G, Fabozzi A, Lieto E, Gambardella V, Morgillo F, et al. Preoperative treatment of locally advanced esophageal carcinoma Int J Oncol. 2013;43(6):1745-53.

10. Orditura M, Galizia G, Sforza V, Gambardella V, Fabozzi A, Laterza MM, et al. Treatment of gastric cancer.World J Gastroenterol. 2014; 20(7):1635-49.

11. Ronellenfitsch U, Schwarzbach M, Hofheinz R, Kienle P, Kieser M, Slanger TE, et al. Preoperative chemo(radio)therapy versus primary surgery for gastroesophageal adenocarcinoma: systematic review with meta-analysis combining individual patient and aggregate data. Eur J Cancer. 2013;49(15):3149-58.

12. Ychou M, Boige V, Pignon JP, Conroy T, Bouché O, Lebreton G, et al. Perioperative chemotherapy compared with surgery alone for resectable gastroesophageal adenocarcinoma: an FNCLCC and FFCD multicenter phase III trial. J Clin Oncol. 2011;29(13):1715-21.

13. Davies AR, Gossage JA, Zylstra J, Mattsson F, Lagergren J, Maisey $\mathrm{N}$, et al. Tumor stage after neoadjuvant chemotherapy determines survival after surgery for adenocarcinoma of the esophagus and esophagogastric junction.J Clin Oncol. 2014;32(27):2983-90.

14. Burmeister BH, Smithers BM, Gebski V, Fitzgerald L, Simes RJ, Devitt $P$, et al. Surgery alone versus chemoradiotherapy followed by surgery for resectable cancer of the oesophagus: a randomised controlled phase III trial. Lancet Oncol. 2005;6(9):659-68.

15. Stahl M, Walz MK, Stuschke M, Lehmann N, Meyer HJ, RieraKnorrenschild J, et al. Phase III comparison of preoperative chemotherapy compared with chemoradiotherapy in patients with locally advanced adenocarcinoma of the esophagogastric junction. $\mathrm{J}$ Clin Oncol. 2009;27(6):851-6.

16. van Hagen $\mathrm{P}$, Hulshof MC, van Lanschot JJ, Steyerberg EW, van Berge Henegouwen MI, Wijnhoven BP, et al. Preoperative chemoradiotherapy for esophageal or junctional cancer. N Engl J Med. 2012; 366(22):2074-84.

17. Orditura M, Galizia G, Di Martino N, Ancona E, Castoro C, Pacelli R, et al. Effect of preoperative chemoradiotherapy on outcome of patients with locally advanced esophagogastric junction adenocarcinoma - a pilot study. Curr Oncol. 2014;21(3):125-33. 
18. Sjoquist KM, Burmeister BH, Smithers BM, Zalcberg JR, Simes RJ, Barbour A, et al. Survival after neoadjuvant chemotherapy or chemoradiotherapy for resectable oesophageal carcinoma: an updated meta-analysis. Lancet Oncol. 2011;12(7):681-92.

19. Macdonald JS, Smalley SR, Benedetti J, Hundahl SA, Estes NC, Stemmermann GN, et al. Chemoradiotherapy after surgery compared with surgery alone for adenocarcinoma of the stomach or gastroesophageal junction. N Engl J Med. 2001:345(10):725-30.

20. Smalley SR, Benedetti JK, Haller DG, Hundahl SA, Estes NC, Ajani JA, et al. Updated analysis of SWOG-directed Intergroup Study 0116: a phase III trial of adjuvant radiochemotherapy versus observation after curative gastric cancer resection. J Clin Oncol. 2012;30(19):2327-33. doi: 10.1200/JC0.2011.36.7136.

21. Markar SR, Karthikesalingam A, Penna M, Low DE. Assessment of short-term clinical outcomes following salvage esophagectomy for the treatment of esophageal malignancy: Systematic review and pooled analysis. Ann Surg Oncol. 2014;21(3):922-31. doi: 10.1245 /s10434-013-3364-0. Epub 2013 Nov 9.

22. Wakui R, Yamashita H, Okuma K, Kobayashi S, Shiraishi K, Terahara A, et al. Esophageal cancer: definitive chemoradiotherapy for elderly patients. Dis Esophagus. 2010;23(7):572-9. doi: 10.1111/1.14422050.2010.01062.x. Epub 2010 Apr 29.

23. Deng N, Goh LK, Wang H, Das K, Tao J, Tan IB, et al. A comprehensive surgery of genomic alterations in gastric cancer reveals systemic patterns molecular exclusivity and co-occurrence among distinct therapeutic targets. Gut. 2012;61(5):673-84. doi:10.1136/gutjnl2011-301839. Epub 2012 Feb 7.

24. The Cancer Genome Atlas Network. Comprehensive molecular characterization of gastric adenocarcinoma. Nature. 2014; 513(7517): 202-9. doi: 10.1038/nature13480. Epub 2014 Jul 23.

25. Cancer Genome Atlas Research Network. Integrated genomic characterization of oesophageal carcinoma. Nature. 2017;541(7636): 169-175. doi: 10.1038/nature20805. Epub 2017 Jan 4.

26. Secrier M, Li X, de Silva N, Eldridge MD, Contino G, Bornschein J, et al. Mutational signatures in esophageal adenocarcinoma define etiologically distinct subgroups with therapeutic relevance. Nat Genet. 2016;48(10):1131-41. doi: 10.1038/ng.3659.

27. Fuchs CS, Tomasek J, Yong CJ, Dumitru F, Passalacqua R, Goswami $\mathrm{C}$, et al. Ramucirumab monotherapy for previously treated advanced gastric or gastro-oesophageal junction adenocarcinoma (REGARD): an international, randomised, multicentre, placebo-controlled, phase 3 trial. Lancet. 2014; 383(9911):31-39. doi: 10.1016/S0140-6736(13) 61719-5.

28. Wilke H, Muro K, Van Cutsem E, Oh SC, Bodoky G, Shimada Y, et al. Ramucirumab plus paclitaxel versus placebo plus paclitaxel in patients with previously treated advanced gastric or gastro-oesophageal junction adenocarcinoma (RAINBOW): a double-blind, randomised phase 3 trial. Lancet Oncol. 2014;15(11):1224-35. doi: 10.1016/ S1470-2045(14)70420-6. Epub 2014 Sep 17.

29. Bang YJ, Van Cutsem E, Feyereislova A, Chung HC, Shen L, Sawaki A, et al. Trastuzumab in combination with chemotherapy versus chemotherapy alone for treatment of HER2-positive advanced gastric or gastro-oesophageal junction cancer (ToGA): a phase 3 , open-label, randomised controlled trial. Lancet. 2010;376(9742): 687-97. doi: 10.1016/S0140-6736(10)61121-X.

30. Crosby T, Hurt CN, Falk S, Gollins S, Mukheriee S, Staffurth J, et al. Chemoradiotherapy with or without cetuximab in patients with oesophageal cancer (SCOPE1): a multicentre, phase 2/3 randomised trial. Lancet Oncol. 2013;14(7):627-37. doi: 10.1016/S1470-2045(13) 70136-0. Epub 2013 Apr 25.

31. Ilson DH, Moughan J, Suntharalingam M, et al. RTOG 0436: A phase III trial evaluating the addition of cetuximab to paclitaxel, cisplatin, and radiation for patients with esophageal cancer treated without surgery. J Clin Oncol 2014;32 suppl:abstr 4007.

32. Bendell JC, Meluch A, Peyton J, Rubin M, Waterhouse D, Webb C, et al. A phase II trial of preoperative concurrent chemotherapy/ radiation therapy plus bevacizumab/erlotinib in the treatment of localized esophageal cancer. Clin Adv Hematol Oncol. 2012;10(7):430-7.

33. Cunningham D, Stenning SP, Smyth EC, et al. Peri-operative chemotherapy with or without bevacizumab in operable oesophagogastric adenocarcinoma (UK Medical Research Council ST03): primary analysis results of a multicentre, open-label, randomised phase 2-3 trial. Lancet Oncol 2017;18:357-70.

34. Muro K, Chung HC, Shankaran V, et al. Pembrolizumab for patients with PD-L1-positive advanced gastric cancer (KEYNOTE-012): a multicentre, open-label, phase $1 \mathrm{~b}$ trial. Lancet Oncol 2016;17:71726.

35. Kang YK, Satoh T, Ryu MH, et al. Nivolumab (ONO-4538/BMS936558) as salvage treatment after second or later-line chemotherapy for advanced gastric or gastro-esophageal junction cancer (AGC): A double-blinded, randomized, phase III trial. J Clin Oncol 2017;35 suppl 4S;abstract 2.

36. Haverkamp L, Seesing MF, Ruurda JP, Boone J, V Hillegersberg R. Worldwide trends in surgical techniques in the treatment of esophageal and gastroesophageal junction cancer. Dis Esophagus. 2017;30(1):1-7. doi: 10.1111/dote.12480.

37. Orringer MB, Sloan H. Esophagectomy without thoracotomy. J Thorac Cardiovasc Surg. 1978;76(5):643-54.

38. Wei MT, Zhang YC, Deng XB, Yang TH, He YZ, Wang ZQ. Transthoracic vs transhiatal surgery for cancer of the esophagogastric junction: a meta-analysis. World J Gastroenterol. 2014;20(29):10183-92. doi: 10.3748/wjg.v20.i29.10183.

39. Hulscher JB, van Sandick JW, de Boer AG, Wijnhoven BP, Tijssen JG, Fockens $\mathrm{P}$, et al. Extended transthoracic resection compared with limited transhiatal resection for adenocarcinoma of the esophagus. N Engl J Med. 2002;347(21):1662-9.

40. Reavis KM, Smith BR, Hinojosa MW, Nguyen NT. Outcomes of esophagectomy at academic centers: an association between volume and outcome. Am Surg. 2008;74(10):939-43.

41. Coupland VH, Lagergren J, Lüchtenborg M, Jack RH, Allum W, Holmberg L, et al. Hospital volume, proportion resected and mortality from oesophageal and gastric cancer: a population-based study in England, 2004-2008. Gut. 2013;62(7):961-6. doi: 10.1136 /gutjnl-2012-303008. Epub 2012 Oct 19.

42. Constantinoiu S. Tratat de patologie și chirurgie esofagiană, Capitolul 16. Editura Academiei Romane: București; 2017. p. 723-785.

43. Bîrlă R, Losif $C$, Gîndea $C$, Hoară $P$, Constantinoiu $S$. Treatment of the esophago-gastric junction adenocarcinoma. Chirurgia (Bucur). 2008;103(2):143-53. Romanian

44. Zhou C, Zhang L, Wang H, Ma X, Shi B, Chen W, et al. Superiority of Minimally Invasive Oesophagectomy in Reducing In-Hospital Mortality of Patients with Resectable Oesophageal Cancer: A MetaAnalysis. PLoS One. 2015;10(7):e0132889. doi: 10.1371/journal. pone.0132889. eCollection 2015.

45. Haverkamp L, Ruurda JP, van Leeuwen MS, Siersema PD, van Hillegersberg R. Systematic review of the surgical strategies of adenocarcinomas of the gastroesophageal junction. Surg Oncol. 2014;23(4):222-8.

46. Gronnier C, Piessen G, Mariette C. Diagnosis and treatment of nonmetastatic esophagogastric junction adenocarcinoma: what are the current options? J Visc Surg. 2012;149(1):e23-33.

47. Chou SH, Kao EL, Chuang HY, Wang WM, Wu DC, Huang MF. Transthoracic or transhiatal resection for middle- and lower-third esophageal carcinoma? Kaohsiung J Med Sci. 2005;21(1):9-14. 